\title{
Human Resource Management in the Indian Banking Sector
}

\author{
Rajwinder Singh \\ School of Management Studies, Punjabi University, Patiala, India \\ Email: rajwindergheer@gmail.com
}

Received May 27, 2013; revised July 11, 2013; accepted July 21, 2013

Copyright (C) 2013 Rajwinder Singh. This is an open access article distributed under the Creative Commons Attribution License, which permits unrestricted use, distribution, and reproduction in any medium, provided the original work is properly cited.

\begin{abstract}
Efficient human resource management is one of the most essential requirements for survival in this competitive world. In this paper, an attempt has been made to test the hypothesis for administrative skills, competitive advantage and human resource development (HRD) policies. This study reveals that Indian bank managers have good administrative skills for industrial competitiveness. Also, they have good administrative skills to manage HRD policies.
\end{abstract}

Keywords: Administrative Skills; Banking Sector; Competitiveness; Human Resource Development; Human Resource Management

\section{Introduction}

To bring out the best in a man is the essence of human resource development. Simply speaking, Human Resource Development (HRD) is the process of increasing the capacity of human resources through the development. Human Resource Development is something that everyone does. Individuals do it as they work to develop themselves; managers do it as they work to support others' development and the Human Resource Development staff does it, as they create the overall development tools for an organization. Thus, it is a process of adding value to individuals, teams and the organization as a human system.

In a larger context, Human Resource Development refers to empowering people and enabling them to use their power for development of the organization to which they belong, and society at large. It refers to developing proactivity and capacity to embrace larger issues. Considering the vital importance of human resources, they are now being treated as assets which are most precious for the survival of an organization. New values are being added. There has been a shift from traditional masterslave relationship to the modern trusteeship system (in which employers and employees are considered as partners investing their wealth and labor respectively) and from traditional salary administration to the new Human Resource System (HRS). With human resources being a part of an organization, HRS is a subsystem of larger system i.e., an organization and Human Resource De- velopment is the center of HRS and most vital for the organizational advancement. Human Resource Development includes both the development of the people and development of an organization.

In this paper, an attempt has been made to test the hypotheses among administrative skills, industrial competitiveness and HRD policies. Pre-pilot survey was done to improve the questionnaire. Later, a pilot survey was conducted and questionnaire was improved and large scale survey was conducted to test and validate the results.

\section{Literature Survey}

The literature survey was conducted on the research topic from leading national and international journal. A brief review of the survey conducted is as follows:

\subsection{National Policy}

Human Resource Development consists of all measures calculated to improve the quality of human resources for the nation as a whole. It embraces within its scope education, health, welfare and such other activities, which are concerned with efficiency and quality of life. Considering the importance of Human Resource Development in the national context, the National Human Resource Development Network and Ministry of Human Resource Development came into existence. The National Human Resource Development is a Network of human resource development of professionals and others 
who are basically concerned with promotion or expansion of the Human Resource Development movement in a country. It is a non-profit organization and a professional body dedicated to the advancement of knowledge, skills, values and attitudes through education, training and experience sharing. The main objectives of national Human Resource Development network include dissemination of knowledge and experience and to facilitate learning among Human Resource Development people, line managers and all employees that have Human Resource Development role to perform.

\subsection{Organizational Policy}

Organizational policy involves the use of processes through which the employees of an organization are prepared to give their best for corporate objectives. It involves setting up of a system through which human capabilities and potentials can be tapped resulting in mutual satisfaction of the individuals and organizations. It is a process by which employees of an organization are continuously helped in a planned way to meet the objectives of an organization. It helps to acquire or sharpen capabilities and improve organizational culture where superior-subordinate relationships, teamwork and collaboration among different subunits are improved for better organizational health, dynamism and pride of employees.

\subsection{Department Policy}

Department policy involves the processes through which employees working within a department are organized to develop and sharpen skill to meet the organizational objectives. It involves the creation of mutual trust, confidence, transparency and improved process to reduce process times in the interest of employees.

In the context of an individual: HRD deals with individual values, behavior, action and thoughts. As such it may be defined as the activities and processes undertaken to promote the intellectual, moral, psychological, cultural, social and economic development of an individual so as to achieve his highest human potential as a resource for the community. In other words, it means an all round development of the person so that he can contribute his best to the organization, the community and the nation.

\subsection{Organizational Efficiency}

Organizational efficiency focuses on the use of money and other resources. Nonprofit organizations measure efficiency based on the relationship between the effectiveness of services and organizational expenditure. On the other-hand business organizations focus on maximization of profits. The organizational performance shall be improved through several channels, including changes in efficiency, innovation and technological development.
The efficient HR practices combined with unions shall influence organizational efficiency [1]. Firms can generate human capital advantage through recruiting and retaining excellent people [2]. This shall help to develop competitive advantage. Also, the practices must be linked to the characteristics of employees, including their expectations and needs [2]. Nelson, [3] suggests that focusing on scarce HR resources, providing insights into how employees create value and employee contribution for the success of the organization.

\subsection{Individual Efficiency}

Increasing personal efficiency and productivity can be a satisfying outcome. Increasing efficiency and productivity comes from changing behaviors, not doing more things. The positive attitude helps in improving personal productivity more than any of the modern electronic gadgets available today.

\subsection{Technological Development}

Technology is the practical application of science to commerce or industry [4]. Human resources tasks cover a large variety of activities requiring different skills ranging from compensation and benefit administration (highly quantitative) to employee relations (highly qualitative) [5]. Walker [6] suggested that HR technology should focus on strategic alignment, business intelligence, efficiency, and effectiveness. It must change the work performed by HR personnel, by improving service level, allowing more time to work of higher value, and reducing their costs. Lewin [7] found that high involvement practices had resulted in significant positive improvement on market value, rate of return on capital employed, revenue growth, revenue-per-employee rate, productivity, product/service quality, and even organizational survival. Also, the use of technology by HR has proven to assist on the improvement of business performances. Sartain [8] clarified that, in order for this to happen, HR should bring the customer's voice to inside an organization, and accomplishing that, upper management will empower HR to reflect the customer's value proposition.

\subsection{Competitive Organization}

Jack [9] quoted that in the competitive market today, keeping the business and its people or human resource (HR) competitive is not easy. Competitiveness is one of the most important roles of HR professionals to play. Competitiveness focuses on the ability to compete in the market by learning new ways of doing business. Dave Ulrich et al. [10] developed a model for understanding the synergies of HR professionals for operational and strategic jobs. The operational aspect focuses on day-today activities on the other-hand strategic aspects have 
become a part of the management of the organization. Flotter et al. [11] presented a framework and suggested to focus on: 1) focus on desired strategic outcomes; 2) identification and implementation of essential human resource management actions; and 3) enhancement of competitive advantage. We need to focus on organization's environment, mission business strategy, and assessment of the human resource requirement to attain competitive advantage.

\subsection{Management Commitment}

It is defined as, "Engaging in and maintaining behavior that help others to achieve a goal". Managers always focus on the best practices for human resource management (HRM). Sometimes this is referred to as "high performance work systems" [12], "high commitment" HRM [13] or "high involvement" HRM [14]. The ultimate objective is to improve the organizational performance by measurement of the same. Cooper et al. [15], classified management measurement as: directly asking questions and monitoring. They also reveal that senior management experts influence more on the employee motivation.

\subsection{Degree of Freedom}

The labor market force is one of the key factors in determining an organization's "degrees of freedom" in HR strategic formation [16]. The demand and availability of particular skills, knowledge and expertise, is a key factor to adopt an appropriate HR strategy. The developments in the economic, political, technological and social spheres have significantly changed the labor requirements. Subsequently, an understanding of the labor market context of work organizations is essential to appreciate the challenges faced by HRM in the twenty-first century. Nike INC. [17], suggested that the focus on clarity of position and freedom, freedom of association training, and building trust and association to arrange and manage labor play important role in improving organizational performance.

\subsection{Efficient Organizational Development}

Bolton and Abdy, [18] quoted that organizational development is about "strengthening organizations so that they can better achieve their mission." Also, it is about being both effective achievement of objectives and efficient use of resources. Hence, it's about doing the right thing; but it's also about doing things right.

\subsection{Objective Achievement}

Human resource management influences many of the key systems; business processes underpinning effective delivery as well as fosters corporate social responsibility eth- ics, and helps to achieve a high performance corporate culture. Human resource management can play a significant role so that corporate social responsibility can become "the way we do things around here" [19]. HR shall be the key organizational partner to ensure that objectives are achieved through and with people, treating them as stakeholders within the organization. Hence, HR should be poised for this leadership role as it is adept at working horizontally and vertically across and within the organization to compete in this competitive world.

\subsection{Cultural Support}

It is a set of common understandings around which action is organized, finding expression in a language whose nuances are peculiar to the group [20]. Becker [20] classified the culture as; weak or strong, inhibitive or facilitative, and consistent or inconsistent. The cultural influences show how members of an organization behave as well perceive to a situation. Heathfield [21] quoted that it is more difficult to change the existing organizational culture than to create a culture in a new organization. When an organizational culture is already established, people must unlearn the old values, assumptions, and behaviors before they can learn the new ones. The most important elements for creating organizational cultural change are executive support and training. Executives in the organization should not only support the cultural changes in ways beyond verbal support but also provide the behavioral support to change the culture. Hence, developing a culture where all the employees work together as team plays an important role to survive in this competitive world.

\subsection{Conflict Management}

In most conflicts the different perceptions collide to create disagreement. Conflict is natural and needs to respond quickly and professionally. It can be resolved formally or informally. Successful conflict resolution occurs by listening to the problems of all the parties and providing the most viable solution. The differences shall be mitigated by stimulating creativity, promoting innovation, and change management. Mismanaged conflicts and disagreements harm important work and workplace relationships. Hence, effectively managed conflict promotes cooperation and builds stronger relationships.

\subsection{Management Attitude}

Lise et al. [22] quoted that the industrial psychology has controversial history related to the study and understanding of employee attitudes and job satisfaction. Some of this research is very specific and aimed primarily at other researchers, while other publications provide practical 
guidance on understanding, measuring, and improving employee attitudes (e.g., 23 \& 24). One likely future direction of employee attitude research will be to better understand the interplay between the person and the situation and the various internal and external factors that influence employee attitudes. In particular, a better understanding of the role of emotion, as well as broader environmental impacts, is needed which has been overlooked in past research. In addition, ongoing research will provide a more in-depth understanding of the effects of employee attitudes and job satisfaction on organizational measures, such as customer satisfaction and financial measures. Greater insights on the relationship between employee attitudes and business performance will assist HR professionals as they strive to enhance the essential people side of the business in a highly competitive, global arena. Agarwal [25] stated that with the adoption of HR policies, such as, periodic review of employee performance, adequate training for the workforce and career advancement norms for its personnel, creating motivation, and commitment in the workforce the organization can reap the full business benefits and become successful to the great satisfaction of all its stakeholders.

\section{Research Hypotheses}

The proposed research hypotheses are shown in Figure 1. It is based on the premise that Indian managers understand the relationship between administrative skills, competitiveness, and HRD policies. These hypotheses are explained as follows:

H1: Indian bank managers have good administrative skills to for industrial competitiveness

The growth trend in the banking sector and vast opportunities has made this sector attractive. Nowadays, bank managers offer vast competitive schemes to attract customers. These schemes shall not be implemented without good administrative skills. To face the competition, the managers have developed sufficient administrative skills to satisfy customers as well as employees to face the competition in this industry. Hence, it leads to:

$\mathrm{H} 2$ : They have developed HRD policies for competitiveness

Nowadays, the banking sector organizes many seminars and development programs to take competitive advantage. The HRD policies are modified for industrial competitiveness. Hence it leads to:

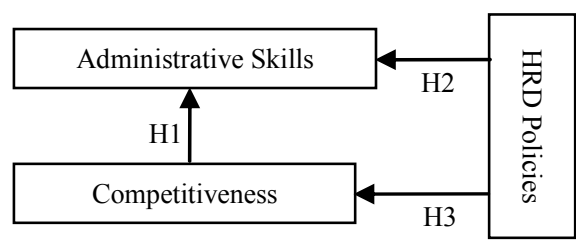

Figure 1. Proposed research framework.
H3: Managers have good administrative skills to develop and manage HRD policies

Taken the things together, has led to the understanding that the managers have good administrative skills to develop and implement HRD policies.

\section{Database and Methodology}

A survey questionnaire has been used as a primary instrument to collect information. The pre-pilot survey was conducted based on a strong literature survey in consultation with practitioners and consultants in the field of banking sector. Based on their responses the necessary corrections were made. Later, pilot survey was conducted and again necessary corrections were made in the questionnaire. In the last full scale survey was conducted in the principal cities of state Punjab, Chandigarh and Delhi. A total of 450 questionnaires were distributed by randomly selecting respondents from; bank organization's web-sites, telephone directory 2010 and PROWESS data base maintained by CMIE. The questionnaires send were followed in response and finally 289 questionnaires were received from respondents operating in the banking sector $(\mathrm{CEO} /$ President/VP/GM/AGM = 25; Managers = 104; Field Supervisor/clerk etc. $=160$ ) yielding a response rate of $64.2 \%$. The questionnaire responses were digitized using SPSS software and scale reliability was done.

A 14-item Likert scale was used to understand the relationship among the manager's administrative skills, HRD policies, and Competitiveness. The seven variables are covered under administrative skills-Management attitude, cultural support, efficient conflict management, objective achievement, efficient organizational development, management commitment, and degree of freedom. The three variables have been covered under HR Policies-organizational policy, department policy and national policy. The four variables have been covered under competitiveness-competitive organization, individual performance organizational performance, and technological development.

The statements/items so developed were rated on a five point Likert scale. Pre-pilot and pilot survey was done to improve the questionnaire. Based on recommendations and suggestions the necessary corrections were made. Later on, large scale survey was conducted in the principal cities of state Punjab, Chandigarh, New-Delhi and Gurgaon.

The items were refined and purified to obtain the reliable scale. For this purpose corrected item-to-total correlation and Cronbach's alpha statistics were used. Item and reliability analysis was performed to retain and delete scale items for the purpose of developing a reliable scale. Corrected item-to-total correlations and Cronbach's alpha statistics were employed to conduct this type of analysis; to know the extent to which any one 
item is correlated with the remaining items in a set of items under consideration.

This analysis found Cronbach's alpha to be 0.9440 and item-to-total correlation rage from 0.8364 to 0.5872 (Table 1) and inter-item correlation is greater than 0.3 . Here, it is pertinent to mention that Alpha value greater than 0.6 and item-to-total correlation greater than 0.5 and inter-item correlation greater than 0.3 is good enough for conducting research in social sciences [26]. The mean for the items is shown in Table 2. If all the 14 items were rated at 5 the total value would be 70 . However, the mean value of 50.3080 indicates that $78.186 \%$ of the items practiced in the banking industry. The results for scale reliability and correlation are shown in Tables 1, 2 and 3.

\subsection{Factor Analysis of Human Resource Management in the Banking Sector}

Hence, the entire requirements for conducting factor analysis were met. The factor analysis was done using Principal component analysis with varimax rotation. The results are shown in Table 3.

\subsection{Results for Structural Model}

The theoretical framework for proposed models is shown in Figure 1. The three hypothesized relationships among competency development, employee motivation and organizational climate are shown. The results of Figure 2 using AMOS 4.0 version showed that the model has Chisquare $=1.227, \mathrm{DF}=24, P=0.00$. All the loadings are

Table 1. Corrected item-to-total correlation, alpha and communality for items of human resource management in the banking sector.

\begin{tabular}{cccc}
\hline CD & $\begin{array}{c}\text { Scale mean if } \\
\text { item deleted }\end{array}$ & $\begin{array}{c}\text { Corrected item-total } \\
\text { correlation }\end{array}$ & $\begin{array}{c}\text { Commonality } \\
\text { Extracted }\end{array}$ \\
\hline A1 & 48.4 & 0.58 & 0.98 \\
A2 & 48.4 & 0.57 & 0.99 \\
A3 & 48.4 & 0.55 & 0.97 \\
B1 & 46.4 & 0.62 & 0.93 \\
B2 & 46.4 & 0.58 & 0.92 \\
B3 & 46.4 & 0.60 & 0.90 \\
B4 & 46.4 & 0.60 & 0.95 \\
C1 & 46.2 & 0.85 & 0.86 \\
C2 & 46.2 & 0.88 & 0.87 \\
C3 & 46.0 & 0.83 & 0.89 \\
C4 & 46.0 & 0.81 & 0.89 \\
C5 & 46.0 & 0.84 & 0.92 \\
C6 & 46.0 & 0.81 & 0.90 \\
C7 & 46.0 & 0.83 & 0.93 \\
\hline
\end{tabular}

Table 2. Mean and standard deviation for items of human resource management in the banking sector.

\begin{tabular}{cccc}
\hline Code & Item (S) & Mean & SD \\
\hline A1 & National Policy & 1.8685 & 0.7840 \\
A2 & Organizational Policy & 1.8720 & 0.7823 \\
A3 & Department Policy & 1.8720 & 0.7823 \\
B1 & Organizational Efficiency & 3.8443 & 0.8333 \\
B2 & Individual Performance & 3.8478 & 0.8193 \\
B3 & Technological Development & 3.8478 & 0.8150 \\
B4 & Competitive Organization & 3.8512 & 0.8304 \\
C1 & Management Commitment & 4.0934 & 0.8302 \\
C2 & Degree of Freedom & 4.1003 & 0.8209 \\
C3 & Efficient Organizational Development & 4.2249 & 0.8708 \\
C4 & Objective Achievement & 4.2318 & 0.8690 \\
C5 & Cultural Support & 4.2180 & 0.8883 \\
C6 & Efficient Conflict Management & 4.2145 & 0.8794 \\
C7 & Management Attitude & 4.2215 & 0.8697 \\
\hline
\end{tabular}

$\mathrm{N}$ of Cases $=289$. Statistics for Scale: Mean $=50.3080 ;$ Variance $=79.0472$; Std Dev $=8.8909 ; \mathrm{N}$ of Variables $=14$. Item Means: Mean $=3.5934 ;$ Minimum $=1.8685 ;$ Maximum $=4.2318 ;$ Range $=2.3633 ; \operatorname{Max} / \operatorname{Min}=2.2648$; Variance $=0.8957$. Inter-item Correlations: Mean $=0.5420 ;$ Minimum $=$ $0.1103 ;$ Maximum $=0.9915 ;$ Range $=0.8812 ;$ Max $/$ Min $=8.9862 ;$ Variance $=0.0682$.

Table 3. Factor analysis results for human resource management in the banking sector.

\begin{tabular}{|c|c|c|c|}
\hline \multirow{2}{*}{ Items } & \multicolumn{3}{|c|}{ Components } \\
\hline & $\begin{array}{l}\text { Administrative } \\
\text { Skills }\end{array}$ & Competitiveness & $\begin{array}{l}\text { HRD } \\
\text { Policies }\end{array}$ \\
\hline Management Attitude & 0.93 & & \\
\hline Cultural Support & 0.91 & & \\
\hline $\begin{array}{l}\text { Efficient Conflict } \\
\text { Management }\end{array}$ & 0.91 & & \\
\hline Objective Achievement & 0.91 & & \\
\hline $\begin{array}{c}\text { Efficient Organizational } \\
\text { Development }\end{array}$ & 0.90 & & \\
\hline Management Commitment & 0.79 & & \\
\hline Degree of Freedom & 0.79 & & \\
\hline Competitive Organization & & 0.95 & \\
\hline Individual Performance & & 0.93 & \\
\hline Organizational Efficiency & & 0.93 & \\
\hline Technological Development & & 0.92 & \\
\hline Organizational Policy & & & 0.96 \\
\hline Department Policy & & & 0.95 \\
\hline National Policy & & & 0.95 \\
\hline Eigen Value & 8.2 & 2.96 & 1.8 \\
\hline$\%$ Variance & 58.9 & 20.6 & 13.0 \\
\hline Cumulative \% Variance & 58.90 & 79.5 & 92.5 \\
\hline Scale Reliability & 0.99 & 0.97 & 0.97 \\
\hline
\end{tabular}

Kaiser-Meyer-Olkin Measure of Sampling Adequacy $=0.867$; Bartlett's Test of Sphericity: Chi-Square $=7538.432 ; \mathrm{DF}=91 ; \mathrm{Sig} .=0.00$. 


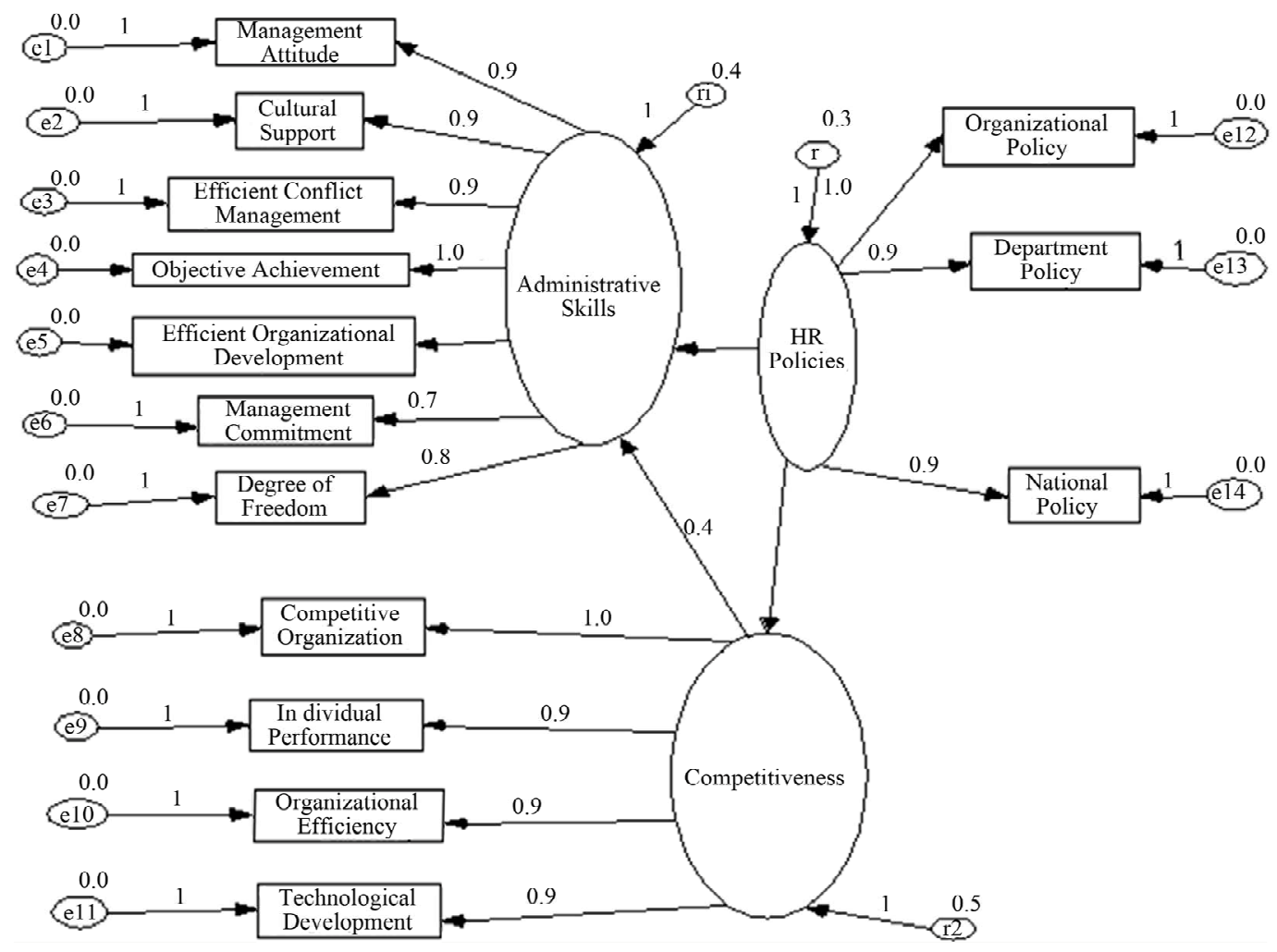

Figure 2. Structural relationship between competency development, employee motivation and organizational climate.

different. The fit measures are $\mathrm{RMR}=0.010, \mathrm{GFI}=$ $0.989, \mathrm{AGFI}=0.980, \mathrm{NFI}=0.986, \mathrm{RFI}=0.979, \mathrm{TLI}=$ 0.96 . The model is significant as the RMR is less than 0.05. The detailed results of analysis are shown in Figure 2.

The effect estimates for structural model are shown in Table 4. The total effect estimate is 0.683 for competency development and organizational climate. It also shows the value of 0.812 for employee motivation and organizational climate. The total effect for employee motivation and competency development is -0.977 . All these values are significant to prove the hypotheses $\mathrm{H} 1$, $\mathrm{H} 2$ and $\mathrm{H} 3$.

\section{Conclusions, Discussion and Limitations}

This paper aims to identify the items for administrative skills, competitiveness and HR policies. The administrative skills have the loading range from 1.0 to 0.7 . All the loadings are significant. The maximum loading has been assigned to objective achievement (1.0). It is due to the fact that this variable is the dominating variable to prove the administrative skills. The efficient conflict management (0.9), cultural support (0.9), management attitude $(0.9)$, degree of freedom (0.8), and management commitment (0.7) also play significant role in administrative skill development. The efficient conflict management shall help to direct the teams towards right goals. The
Table 4. Effect estimates for structural model (Figure 2).

\begin{tabular}{|c|c|c|c|c|}
\hline Efcts & Factors & HRD Pol & Cmpt. & Adm Skl \\
\hline \multirow{2}{*}{$\begin{array}{c}\text { Total } \\
\text { Effect }\end{array}$} & Competitiveness & 0.084 & 0.000 & 0.000 \\
\hline & Administrative Skills & 0.678 & 0.430 & 0.000 \\
\hline \multirow{2}{*}{$\begin{array}{l}\text { Direct } \\
\text { Effect }\end{array}$} & Competitiveness & 0.084 & 0.000 & 0.000 \\
\hline & Administrative Skills & 0.642 & 0.430 & 0.000 \\
\hline \multirow{2}{*}{$\begin{array}{l}\text { Indirect } \\
\text { Effect }\end{array}$} & Competitiveness & 0.000 & 0.000 & 0.000 \\
\hline & Administrative Skills & 0.036 & 0.000 & 0.000 \\
\hline
\end{tabular}

Chi-square $=378.758, \mathrm{DF}=74, \mathrm{P}=0.000, \mathrm{RMR}=0.05, \mathrm{GFI}=0.82, \mathrm{AGFI}$ $=0.80, \mathrm{TLI}=0.84, \mathrm{CFI}=0.802$. Model is Significant.

cultural support shall help in understanding and managing the workplace. It is also required to influence the management attitude for the betterment of employee as well as the organization. Hence, management of commitment is also an important variable for administrative skill development. The employees should also be given freedom to work in the right direction for betterment of the business.

The competitiveness has also significant loading of all the variables-competitive organization (1.0), individual performance (0.9), organizational efficiency (0.9), and technological development (0.9). All the loadings are significant. The maximum loading for competitive organization shows that this variable is the most dominat- 
ing. It is due to the fact that to survive in this competitive world, the organizations need to develop competitive spirit. It is also needed to upgrade technology from time to time for efficient return. These developments are not sufficient without the focus on individual as well as organizational performance.

The HR policies also have significant loading - organizational policy (1.0), departmental policy (0.9), and national policy (0.9). All the loadings are significant. The maximum loading of organizational policy shows that rules and regulations should be uniform. Also, the departmental policy should be without bias. The government should also develop a uniform national policy to minimize conflicts and dissatisfaction.

The Total Effect estimates have been shown in Table 4. The Total Effect of Administrative Skills on HR Policies is 0.678. Hence, it proves the hypothesis (H3): Managers have good administrative skills to develop and manage HRD policies. The Total Effect of Administrative Skills on Competitiveness is 0.430 . It clearly proves the hypothesis (H1): Indian bank managers have good administrative skills for industrial competitiveness. Also, the Total Effect of Competitiveness on HR Policies (0.084) proves the hypotheses (H2): They have developed HRD policies for competitiveness.

All the Total Effects are significant. Also, the results of the study are in consonance with the studies quoted in the literature review. However, despite the statistical sophistication of structural equation modeling, this study has the major limitations as few of the lot of top management participated in the study. Here, it is pertinent to mention that these people are instrumental to develop policies and procedures for Administrative Skills, HR Policies, and Competitiveness. Also, the microscopic structure of the organizations is very complex in nature due to different attitude and perception of the respondents. Hence, for more detailed analysis of these, the groups and subgroups of the people are also needed to be studied.

\section{REFERENCES}

[1] D. Hristos and L. Patrice, "Human Resource Practices, Unionization and the Organizational Efficiency of French Industry," In: D. Lewin and B. E. Kaufman, Eds., Advances in Industrial \& Labor Relations, Vol. 15, Emerald Group Publishing Limited, 2006, pp. 67-102.

[2] P. Boxall, "The Strategic HRM Debate and the Resource Based View of the Firm," Human Resource Management Journal, Vol. 6, No. 3, 1996, pp. 59-75. doi:10.1111/j.1748-8583.1996.tb00412.x

[3] J. Nelson, "HR Focus Efficiency and Effectiveness," 2010. http://www.yourhrremedy.com/news/?p=18

[4] B. Luck, "Innovation of Technology: Business for a New Century," 2010.
http://www.scribd.com/doc/27947709/Innovation-of-Tec hnology-in-Business-Slides

[5] R. Kenter, "Foreword," In: M. Effron, R. Gandossy and M. Goldsmith, Eds., Human Resources in the 21st Century, John Wiley \& Sons, Hoboken, 2003, p. 12.

[6] A. Walker, "Best Practices in HR Technology," In: A. Walker and T. Perrin, Eds., Web-Based Human Resources: The Technologies and Trends That Are Transforming HR, 2001, pp. 3-14.

[7] D. Lewin, "Human Resource Management and Business Performance," In: M. Effron, R. Gandossy and M. Goldsmith, Eds., Human Resources in the 21st Century, John Wiley \& Sons, Hoboken, 2003, pp. 91-98.

[8] L. Sartain, "Branding from Inside Out: HR's Role as Brand Builder,” In: M. Losey, S. Meisinger and D. Ulrich, Eds., The Future of Human Resource Management: 64 Thought Leaders Explore the Critical HR Issues of Today and Tomorrow, John Wiley \& Sons, Hoboken, 2005, pp. 181188.

[9] W. Jack, "Building a Competitive Organization through HRM Initiatives: A Macro Perspective, Street Smart Human Resource Management \& Business Practices," 2007. http://www.hrmbusiness.com/2009/08/building-competiti ve-organizations.html

[10] D. Ulrich, R. Michael and G. Losey, “Tomorrow's HR Management," John Wiley \& Sons, Inc., New York, 1997.

[11] M. D. Fottler, R. L. Phillips, J. D. Blair and C. A. Duran, "Achieving Competitive Advantage through Strategic Human Resource Management," Hospital Health Service Administration, Vol. 35, No. 3, 1990, pp. 341-363.

[12] H. Ramsay, D. Scholarios and B. Harley, "Employees and High-Performance Work Systems: Testing Inside the Black Box," British Journal of Industrial Relations, Vol. 38, No. 4, 2000, pp. 501-531. doi:10.1111/1467-8543.00178

[13] D. Guest, J. Michie, M. Sheehan, N. Conway and M. Metochi, "Effective People Management: Initial Findings of the Future of Work Study," CIPD, London, 2001.

[14] B. Wood, W. Doellgast, M. Legge and I. Grugulis, “"Best Practice' Human Resource Management: Perfect Opportunity or Dangerous Illusion?" International Journal of Human Resource Management, Vol. 11, No. 4, 2000, pp. 905-925.

[15] D. Cooper, C. Psychd and C. Fiosh, "The Impact of Management's Commitment on Employee Behaviour: A Field Study," American Society of Safety Engineer, 2006. http://www.behavioral-afety.com/articles/Impact_of_Man agement_Commitment.pdf

[16] P. Boxall and J. Purcell, "Strategy and Human Resource Management," Palgrave Macmillan, Basingstoke, 2003.

[17] Nike Inc., "Workers and Factories," 2008. http://www.nikebiz.com/crreport/content/workers-and-fac tories/3-8-0-freedom-of-association.php?cat=freedom-ofassociation

[18] M. Bolton and M. Abdy, "Foundations for Organizational Development Practices in the UK and USA," 2007. http://www.efc.be/CapacityBuilding/Documents/Foundati ons_for_Organizational_Development.pdf

[19] S. Coro, "The Role of Human Resource Management in 
Corporate Social Responsibility," Strandberg Consultants, 2009, pp. 1-26.

http://corostrandberg.com/wp-content/uploads/files/CSR and_HR_Management1.pdf

[20] H. S. Becker and B. Geer, "Participant Observation: The Analysis of Qualitative Field Data," In: R. Adams and J. Preiss, Eds., Human Organization Research, The Dorsey Press, Homewood, 1960.

[21] S. M. Heathfield, "How to Change Your Culture: Organizational Culture Change," 2008.

http://humanresources.about.com/od/organizationalculture/ a/culture_change_2.htm

[22] M. S. Lise and A. J. Timothy, "Employee Attitudes and Job Satisfaction," Human Resource Management, Vol. 43, No. 4, 2004, pp. 395-407. doi:10.1002/hrm.20032
[23] J. E. Edwards and B. M. Fisher, "Evaluating Employee Survey Programs," In: J. E. Edwards, J. C. Scott and N. S. Raju, Eds., The Human Resources Program-Evaluation Handbook, Sage, Thousand Oaks, 2004, pp. 365-386.

[24] A. I. Kraut, "Organizational Surveys: Tools for Assessment and Change," Jossey Bass, San Francisco, 1996.

[25] K. Agarwal, "Corporate Excellence as an Outcome of Corporate Governance: Rethinking the Role and Responsibility of HRM," The ICFAI Journal of Corporate Governance, Vol. 6, No. 1, 2007, pp. 6-16.

[26] J. F. Hair, W.C. Black, B. J. Babin, R. E. Anderson and R. L. Tatham, "Multivariate Data Analysis," Pearson Education Inc., Delhi, 2009. 